\title{
REVIEW
}

\section{Impact of the Topical Ophthalmic Corticosteroid Loteprednol Etabonate on Intraocular Pressure}

\author{
John D. Sheppard · Timothy L. Comstock · Megan E. Cavet
}

Received: February 5, 2016/Published online: March 17, 2016

(C) The Author(s) 2016. This article is published with open access at Springerlink.com

\begin{abstract}
Corticosteroids are a mainstay therapeutic option for the treatment of ocular inflammation. However, safety remains a concern for clinicians, particularly with long-term use. Though highly effective at suppressing inflammatory and allergic responses, topical ophthalmic corticosteroids carry an inherent risk of side effects, including elevated intraocular pressure (IOP), a risk factor for the development of glaucoma. The corticosteroid loteprednol etabonate (LE) contains an ester rather than a ketone at the C-20 position, minimizing the potential for side effects, including IOP elevation. In early pivotal
\end{abstract}

Enhanced content To view enhanced content for this article go to http://www.medengine.com/Redeem/0C44 F0606370E8F1.

J. D. Sheppard

Department of Ophthalmology, Eastern Virginia

Medical School, Norfolk, VA, USA

T. L. Comstock

Rochester, NY, USA

M. E. Cavet $(\square)$

Medical Affairs, Bausch + Lomb, Rochester,

NY, USA

e-mail: Megan.Cavet@bausch.com clinical trials of LE ophthalmic suspension for conjunctivitis (allergic, giant papillary), anterior uveitis, and post-operative inflammation, LE had minimal impact on IOP over short-term ( $<28$ days) and long-term ( $\geq 28$ days) use. Since then, new LE formulations-including a gel, an ointment, and a suspension of LE in combination with tobramycin-have become commercially available. Multiple studies evaluating the safety and efficacy of LE for inflammatory conditions have been reported, including those requiring longer-term treatment such as photorefractive keratectomy, corneal transplantation, and dry eye disease. We review the available published data on the effect of LE on IOP and report on the cumulative incidence of clinically significant IOP elevations ( $\geq 10 \mathrm{~mm} \mathrm{Hg}$ from baseline) with short-term and long-term LE use. In all studies, LE consistently demonstrated a low propensity to elevate IOP, regardless of formulation, dosage regimen, or treatment duration, including in known steroid responders. The cumulative proportion of patients exhibiting clinically significant IOP increases was $0.8 \%(14 / 1725$ subjects) in studies evaluating short-term LE treatment and $1.5 \%(21 / 1386$ subjects $)$ in 
long-term studies. Furthermore, use of LE was associated with significantly lower rates of IOP elevation $\geq 10 \mathrm{~mm} \mathrm{Hg}$ as compared to prednisolone acetate or dexamethasone (when used in combination with tobramycin). The cumulative data to date substantiates a favorable IOP-safety profile for LE with both short-term and long-term use.

Keywords: Corticosteroid; Glaucoma; Intraocular pressure; Loteprednol etabonate; Ophthalmology; Safety; Topical ophthalmic

\section{INTRODUCTION}

Topical corticosteroids are widely used to treat inflammatory conditions of the ocular surface and the anterior segment. Acting through the cytosolic glucocorticoid receptors and exerting their effects predominantly at the genomic level, corticosteroids possess broad mechanisms of action and potent anti-inflammatory activity [1-3]. By inhibiting upstream phospholipase A2, they block both the cyclooxygenase and lipoxygenase pathways of the inflammatory cascade and thus prevent formation of all eicosanoids [2, 3]. In addition, they are known to inhibit inflammatory cytokines, chemokines, adhesion molecules, and other inflammatory mediators [1, 4]. These pathways are involved in the progression of many ocular surface and anterior segment inflammatory conditions, including post-surgical inflammation, anterior uveitis, blepharitis, and dry eye. Additionally, corticosteroids reduce synthesis of histamine, stabilize cell membranes, and inhibit degranulation of mast cells, making topical corticosteroids an effective treatment for ocular allergic inflammatory conditions $[5,6]$.
In addition to their therapeutic effects, corticosteroids can produce a number of adverse side effects, including cataract formation, increased susceptibility to microbial infection, delayed wound healing, and, the focus of this review, intraocular pressure (IOP) elevation [7, 8]. Corticosteroid-induced ocular hypertension may occur with any mode of administration, but is much more common with topical corticosteroids than with corticosteroid systemic therapies [9-11]. Besides the active moiety itself, factors contributing to the IOP-raising potential of a specific topical corticosteroid include ocular pharmacokinetics, dosage, and treatment duration [7, 12]. IOP elevation has been found to be common with older corticosteroids such as dexamethasone and prednisolone [12, 13]. Difluprednate, one of the newer corticosteroids and a difluorinated derivative of prednisolone, also demonstrates a higher propensity to raise IOP in comparison to corticosteroids such as LE and rimexolone [12]. It has long been recognized that, in the general adult population, about one-third will experience IOP elevations of $6-15 \mathrm{~mm} \mathrm{Hg}$ (moderate responders) and 4-6\% will experience IOP elevations $>15 \mathrm{~mm} \mathrm{Hg}$ (high responders) following 4-6 weeks of topical corticosteroid therapy [14-16]. These "steroid responders" usually have predisposing factors, such as a family history of glaucoma, diabetes mellitus, myopia, or younger age $[9,17-20]$. When this IOP increase persists, patients may develop glaucomatous optic nerve damage and irreversible vision loss $[7,9,19]$.

The exact mechanism of steroid-induced IOP elevation is not fully understood. Genetics clearly play a role in steroid-induced glaucoma. Studies have shown that corticosteroids can cause multiple 
physiological changes in the main aqueous humor outflow pathway, the trabecular meshwork. These changes include the formation of cross-linked actin fibers, increased deposition of extracellular matrix material, and inhibition of cell phagocytosis, which together result in an increased resistance to aqueous outflow and thus elevation of IOP [9, 12]. Multiple genes are upregulated in glaucoma, with the most well studied being myocilin which encodes a $55 \mathrm{kDa}$ secreted protein [9]. Mutations in the myocilin gene are linked to both juvenile and adult-onset glaucoma. The protein myocilin is upregulated in trabecular meshwork cells exposed to steroids. However, the precise mechanism(s) by which myocilin causes glaucoma remains to be elucidated [9].

Loteprednol etabonate (LE) is unique among corticosteroids in that the drug molecule incorporates a metabolically labile moiety which allows rapid metabolism and degradation following glucocorticoid receptor activation, thereby imparting a lower risk of side effects [21-23]. Unlike other ophthalmic corticosteroids, LE contains a chloromethyl ester instead of a ketone moiety at the carbon 20 (C-20) position of the prednisolone acetate (PA) core structure (Fig. 1). The metabolically labile C-20 ester group undergoes predictable hydrolysis by endogenous esterases into inactive metabolites (Fig. 1). In addition, LE is highly lipophilic and binds the glucocorticoid receptor with 4.3-fold greater affinity than dexamethasone [24]. LE also retains the high potency of prednisolone, with an anti-inflammatory efficacy 20-fold higher than hydrocortisone [22]. These attributes enable LE to penetrate the ocular tissues including the conjunctiva, cornea, and iris-ciliary body, bind to the glucocorticoid receptor, and exert potent anti-inflammatory effects, with minimal propensity for side effects [21-23, 25].

LE was approved in 1998 by the US Food and Drug Administration (FDA) in two ophthalmic formulations. $\quad$ Lotemax $^{\circledR} \quad$ ophthalmic suspension $0.5 \%$ (Bausch + Lomb, Tampa, FL, USA) is indicated for the treatment of various ocular surface and anterior segment inflammatory conditions and postoperative inflammation following ocular surgery. Alrex ${ }^{\circledR}$ ophthalmic suspension, 0.2\% (Bausch + Lomb) is indicated specifically for temporary relief of the signs and symptoms of seasonal allergic conjunctivitis. Both products were well tolerated and had minimal impact on IOP in phase III randomized clinical trials performed for the original US FDA approval of LE [26-33]. Novack and colleagues [34] evaluated the

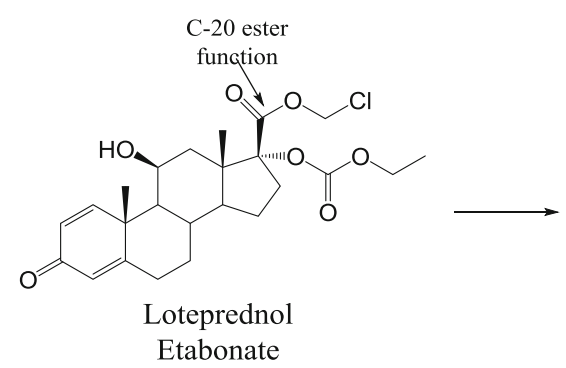

Fig. 1 Molecular structure of LE and its inactive metabolites. LE is a $17 \beta$-chloromethylester derivative of $\Delta 1$-cortienic acid, an inactive metabolite of prednisolone;

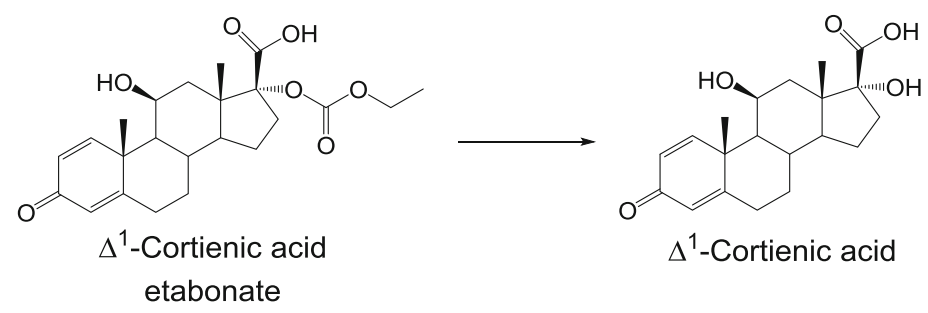

LE also has a $17 \alpha$-etabonate moiety. LE undergoes rapid deesterification to the inactive $\Delta 1$-cortienic acid after exerting its effect. $L E$ loteprednol etabonate 
potential of LE to elevate IOP with long-term use across all preapproval LE clinical studies. A total of 1648 healthy volunteers and patients with ocular inflammation or allergy who were treated with LE $(0.2 \%$ or $0.5 \%)$, PA $1 \%$, or vehicle for $\geq 28$ days were included in this retrospective meta-analysis. Significant IOP elevation (defined as $\geq 10 \mathrm{~mm} \mathrm{Hg}$ above baseline) occurred in $1.7 \%(15 / 901)$ of subjects receiving LE, in $6.7 \%(11 / 164)$ of subjects receiving $\mathrm{PA} 1 \%$, and in $0.5 \%(3 / 583)$ of subjects receiving vehicle. LE $0.2 \%$ had a similar effect upon IOP as vehicle, with one subject developing IOP elevation in each treatment group $(0.8 \%$ or $1 / 133$ for LE $0.2 \%$; $0.7 \%$ or $1 / 135$ for vehicle). Excluding patients who wore contact lenses during treatment, $0.6 \%(4 / 624), 1 \%(3 / 304)$, and $6.7 \%(11 / 164)$ of subjects receiving LE, vehicle, and PA experienced an IOP elevation. The authors concluded that the suspension formulations of LE $0.2 \%$ and $0.5 \%$ had a low propensity to cause clinically significant IOP elevations. For the purpose of this review, the same criterion of $\geq 10 \mathrm{~mm} \mathrm{Hg}$ above baseline is used to define clinically significant IOP elevation unless otherwise specified. Where available, data on IOP elevations of $\geq 5 \mathrm{~mm} \mathrm{Hg}$ are also reported.

Several new ophthalmic formulations of LE have been approved for topical ophthalmic use following Novack et al.'s meta-analysis [34]. LE is now commercially available in the USA as an ointment (Lotemax ophthalmic ointment 0.5\%; Bausch + Lomb), a gel (Lotemax ophthalmic gel 0.5\%; Bausch + Lomb), and in combination with tobramycin (Zylet $^{\circledR} \quad$ LE $0.5 \%$ and tobramycin $0.3 \%$ ophthalmic suspension; Bausch + Lomb). The efficacy of LE formulations in the treatment of ocular inflammatory conditions including the treatment of ocular pain and inflammation following cataract surgery, uveitis, and seasonal allergic conjunctivitis and blepharokeratoconjunctivitis has been demonstrated in randomized controlled trials and is the subject of several recent reviews [35-37]. This article summarizes published data to date on the safety of LE in the treatment of numerous ocular inflammatory conditions, with a specific focus upon IOP effects.

\section{METHODS}

A literature search was conducted for English language articles using PubMed, Embase, Biosis Previews, and Medline, using "loteprednol etabonate" as the single search term, with no time limitations through December 2015. Clinical studies that report original quantitative data on the impact of LE on IOP were identified and reviewed. In addition, relevant conference abstracts were included where the data were not available in full manuscript form. A brief summary of early clinical trials that characterized the safety of LE when used in the treatment of ocular inflammation is followed with a comprehensive review of additional safety data on LE from studies published since the meta-analysis by Novack et al. [34]. Finally, we calculated the cumulative incidence of clinically significant elevations in IOP, defined as $\geq 10 \mathrm{~mm} \mathrm{Hg}$, with short-term or long-term administration of LE across all relevant clinical studies to date. The overall elevations in IOP with the use of LE compared to vehicle, dexamethasone, or PA were calculated from head-to-head studies. Incidence rates were based on the safety population (i.e., those subjects that instilled study drug) wherever reported. Significant differences $(P<0.05)$ between groups were determined using a 
two-tailed $Z$ test with Yates correction using SigmaPlot 11.0 (Systat Software, Inc.).

This article is based on previously conducted studies and does not involve any new studies of human or animal subjects performed by any of the authors.

\section{LE SUSPENSION IOP SAFETY PROFILE: EARLY PIVOTAL TRIALS}

Tables 1 and 2 provide a summary of all LE studies cited in the review, categorized by treatment duration (i.e., short term $\leq 28$ days and long term $\geqq 28$ days). The effect of LE on IOP was evaluated in randomized, double-masked, vehicle-controlled studies performed for the initial marketing approval of LE in the USA. Two trials evaluated the safety and efficacy of LE ophthalmic suspension $0.5 \%$ administered four times a day for 2 weeks in controlling postoperative inflammation and pain after cataract surgery. One of the studies reported no clinically significant elevation of IOP ( $\geq 10 \mathrm{~mm} \mathrm{Hg}$ ) in the LE treatment group [26], while the other found a clinically significant, yet transient IOP increase in 3\% of LE-treated patients [33]. The efficacy and safety of LE $0.5 \%$ was compared to that of PA $1 \%$ (Pred Forte $^{\circledR}$, Allergan, Irvine, CA, USA) in patients with acute anterior uveitis in two clinical trials [27]. In the first study, medications were administered up to eight times daily initially and continued at a reduced frequency for up to 42 days, while in the second study, medications were administered up to 16 times daily initially and continued at a reduced frequency for up to 28 days. In both studies, the safety profile of LE was more favorable with fewer incidences of IOP increase $\geq 10 \mathrm{~mm} \mathrm{Hg}$ (overall 1/115) than the PA group (overall 7/121). Dell et al. [29, 30] assessed the efficacy and safety of LE $0.5 \%$ and $0.2 \%$ ophthalmic suspensions administered four times daily in the treatment of seasonal allergic conjunctivitis in two clinical studies conducted over a period of 6 weeks. None of the LE-treated patients in the studies developed a clinically significant IOP elevation, while between $4 \%$ and $10 \%$ of LE patients had an elevation of $\geq 6 \mathrm{~mm} \mathrm{Hg}$ versus $1-7 \%$ of vehicle-treated patients at each study visit with LE $0.5 \%$. In addition, Shulman et al. [32] observed no difference in the incidence of clinically significant IOP elevations between the LE $0.2 \%(1 / 67)$ and vehicle (1/68) groups during 6 weeks of treatment (four times daily regimen) in a randomized, controlled multi-center study of 135 patients with seasonal allergic conjunctivitis. The safety and efficacy of LE $0.5 \%$ applied four times daily for 6 weeks in patients with contact lens-related giant papillary conjunctivitis were assessed in two clinical trials $[28,31]$. A transient IOP elevation $\geq 10 \mathrm{~mm} \mathrm{Hg}$ was observed in $3 \%$ and $7 \%$ of LE-treated patients, while there was no IOP elevation in the vehicle-treated groups in the two studies. Using the criterion of $\geq 6 \mathrm{~mm} \mathrm{Hg}, \quad 15 \%$ and $25 \%$ of LE-treated patients compared to $4 \%$ and $10 \%$ of vehicle-treated patients were observed to have an elevation in IOP in the two studies. Patients were permitted to continue to wear their lenses during these trials, and therefore concomitant use of LE with contact lenses may slightly increase the risk of IOP elevations, as is the case for other corticosteroids. Thus, a presumed depot effect should be considered when prescribing LE to contact lens users or patients using a therapeutic bandage contact lens. 


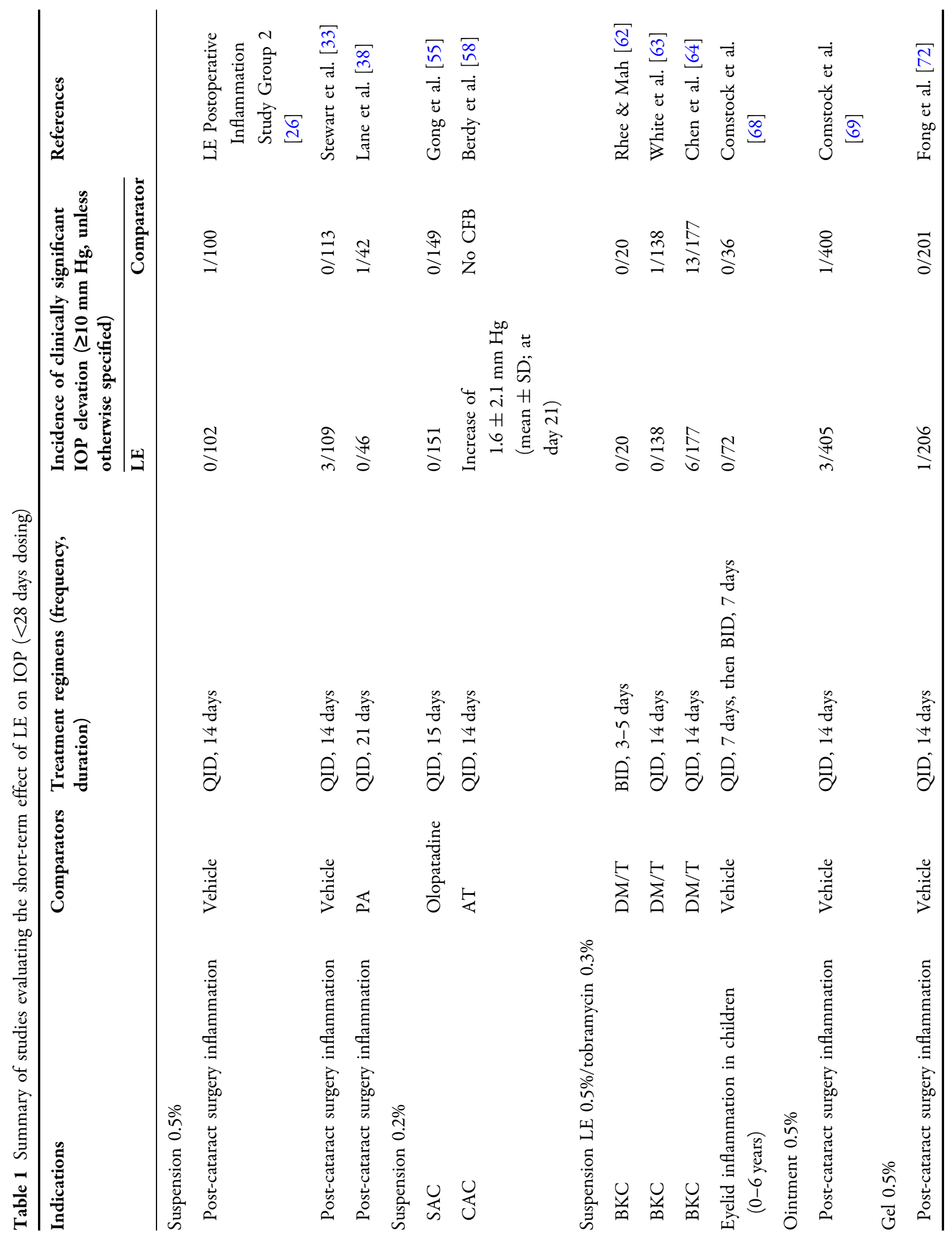




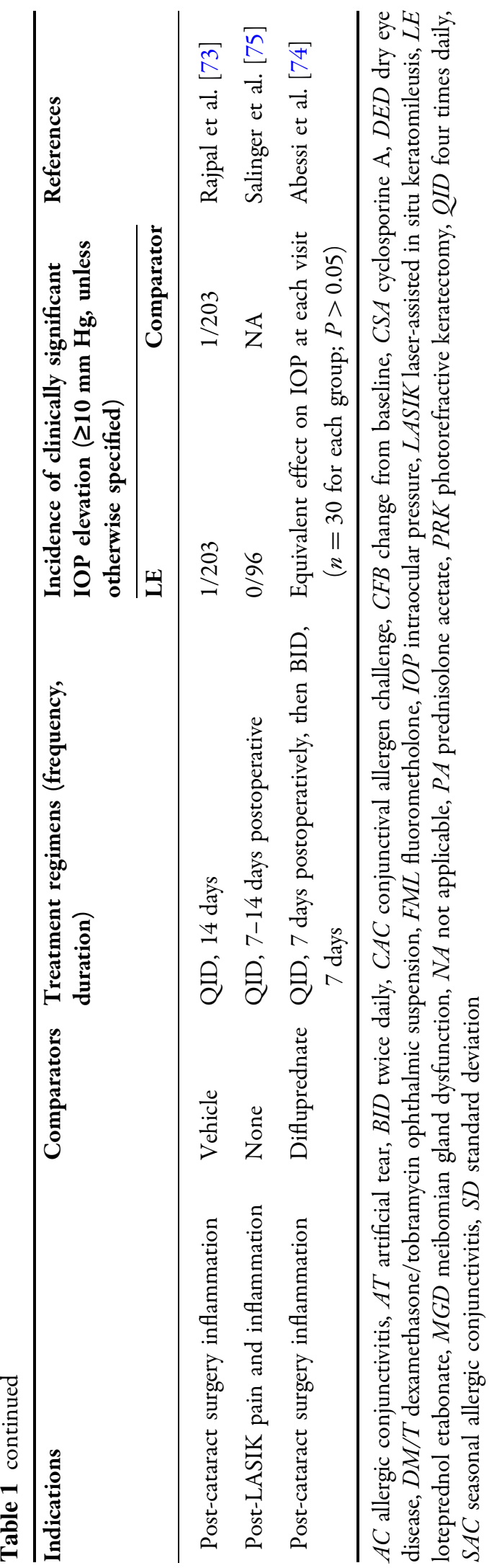

\section{LE SUSPENSIONS: IOP DATA FROM MORE RECENT STUDIES}

Multiple studies evaluating the safety and efficacy of LE have been reported in the literature since the publication of the early pivotal trials, both studies with short-term treatment (summarized in Table 1) and studies requiring long-term treatment for ocular inflammation following various surgical procedures and dry eye disease (DED; summarized in Table 2).

\section{Cataract and Refractive Surgery}

Comparative studies of LE suspension $0.5 \%$ and other anti-inflammatory agents support earlier findings that LE $0.5 \%$ has a low impact on IOP when used for postoperative inflammation and pain following cataract surgery. Lane and Holland [38] compared the effects of LE 0.5\% and PA 1.0\% (Pred Forte), administered four times daily for 3 weeks, on postoperative inflammation in a multi-center, investigator-masked, randomized study in 88 patients after routine cataract surgery. Throughout the 3-week follow-up, LE-treated patients had a lower mean elevation of IOP than patients treated with PA, though the difference was not statistically significant. None of the LE-treated patients developed clinically significant IOP elevation, while one PA-treated patient had a $>10 \mathrm{~mm} \mathrm{Hg}$ elevation in IOP 7 days after surgery.

Two prospective studies evaluated the comparative efficacy and safety of LE ophthalmic suspension $0.5 \%$ and topical nonsteroidal anti-inflammatory drugs (NSAIDs) in reducing inflammation after uncomplicated cataract surgery $[39,40]$. In an open-label study, Bannale et al. [39] showed similar tolerability and safety profiles of LE $0.5 \%$ and flurbiprofen 


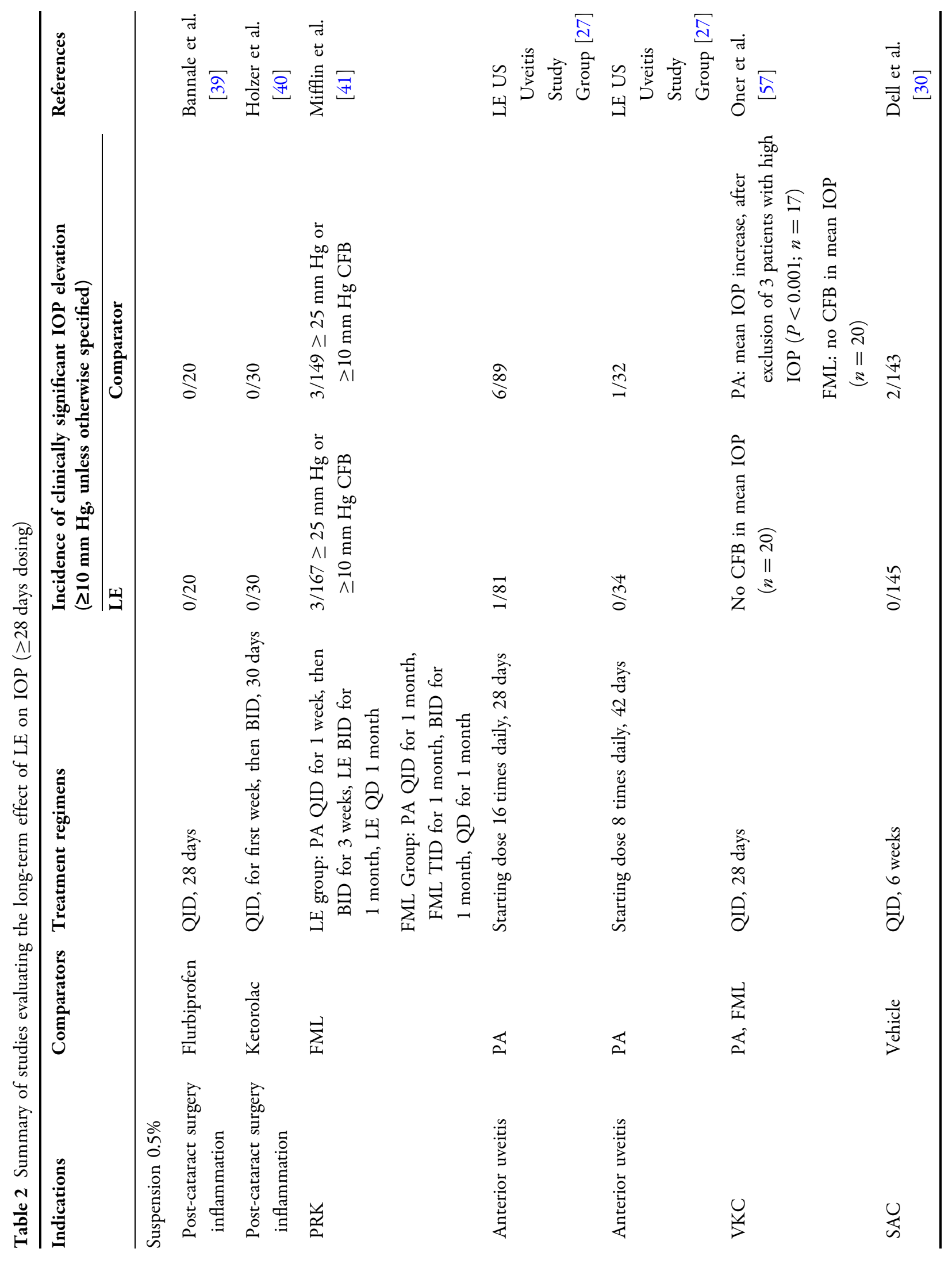




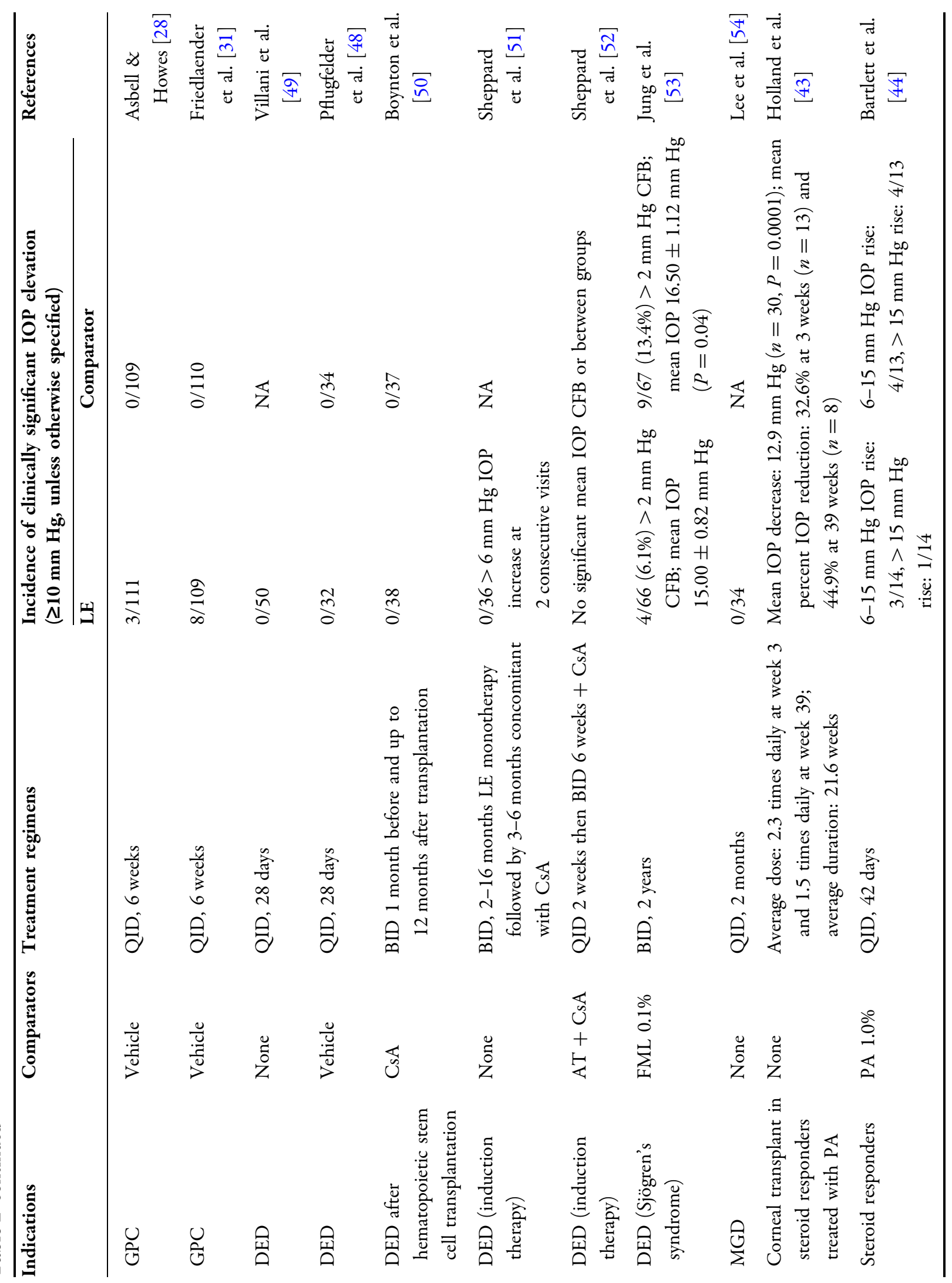




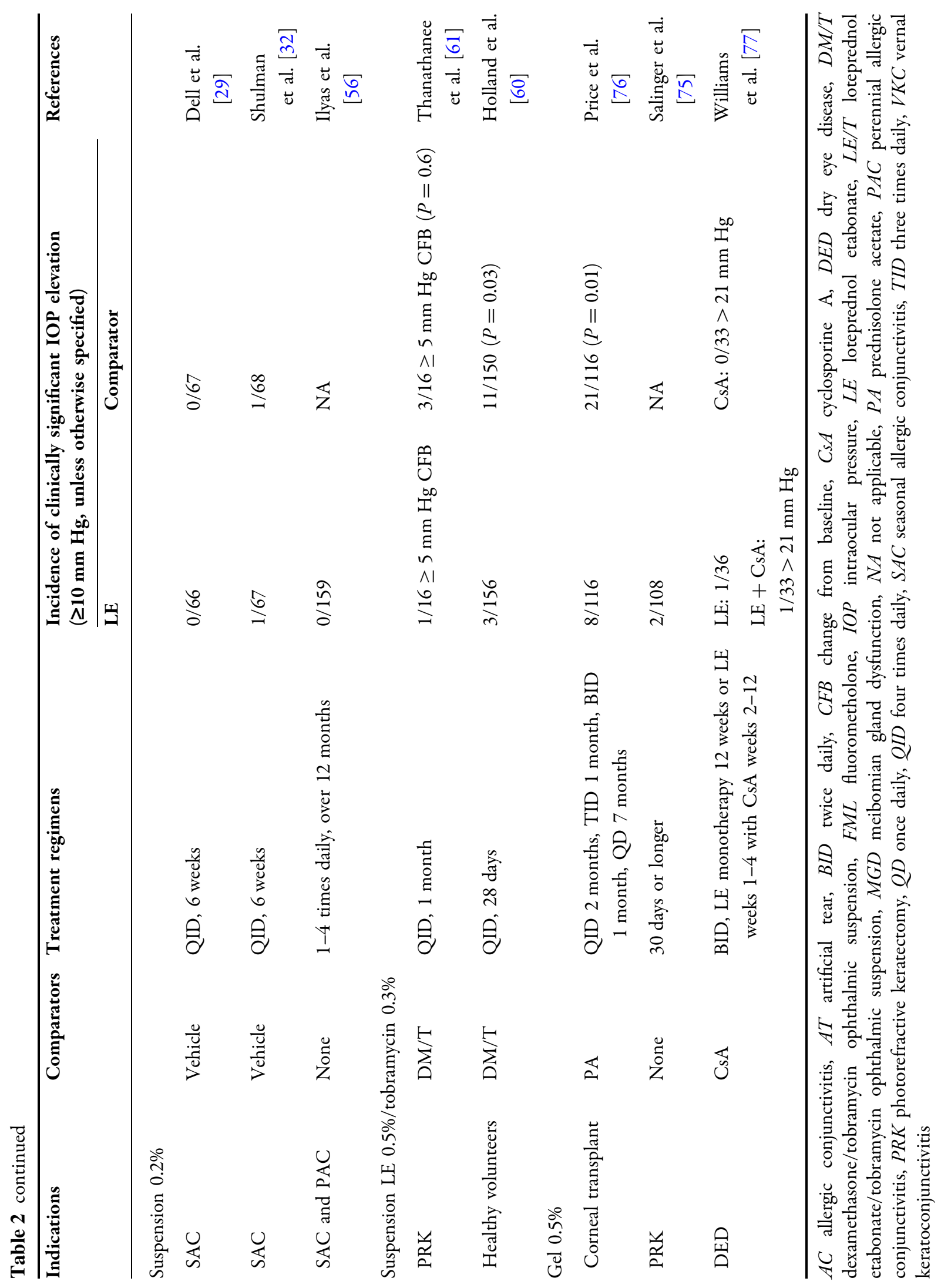


sodium $0.03 \%$ administered postoperatively four times daily for 4 weeks, with no reports of clinically significant IOP elevation in patients receiving either treatment $(n=20)$. Holzer et al. [40] compared the safety and efficacy of LE with those of ketorolac tromethamine $0.5 \%$ in a randomized double-masked study of 60 patients undergoing cataract surgery. The anti-inflammatory agents were administered four times a day for the first week (starting $24 \mathrm{~h}$ after surgery) and then two times a day for a total of 30 days. There were no differences in mean IOP between the two treatment groups at any time, with mean [ \pm standard deviation (SD)] IOP ranging from $12.0 \pm 3.8$ to $15.1 \pm 3.8 \mathrm{~mm} \mathrm{Hg}$ in the LE group and $13.7 \pm 3.1$ to $16.0 \pm 2.8 \mathrm{~mm} \mathrm{Hg}$ in the ketorolac group. The highest IOP readings (23 and $24 \mathrm{~mm} \mathrm{Hg}$ ) were measured in two patients in the LE group 1 month postoperatively; however, these patients had baseline (preoperative) IOP values of 25 and $24 \mathrm{~mm} \mathrm{Hg}$, respectively.

The comparative safety of LE suspension $0.5 \%$ and fluorometholone (FML) $0.1 \%$ were evaluated in patients undergoing photorefractive keratectomy (PRK) in a retrospective analysis of 579 eyes of 316 patients [41]. All patients had PA 1\% instilled four times daily in the first postoperative week, followed by either PA 1\% two times daily for 3 weeks, followed by LE $0.5 \%$ twice daily for 1 month and then once daily for 1 month (12 weeks in total), or PA $1 \%$ four times daily for three more weeks followed by FML $0.1 \%$ three times daily for a month, tapered by one drop per day per month (16 weeks in total). The results showed LE suspension $0.5 \%$ and FML $0.1 \%$ were both associated with a low incidence of elevated IOP (fewer than three patients at months 2 and 3) when incorporated into treatment protocols for the prevention of post-PRK haze.

\section{High-Risk Groups}

The potential for a corticosteroid to raise IOP is proportional to the duration of treatment [7, 19]. IOP increase is, therefore, a particular concern for patients who require prolonged use of topical corticosteroids. Post-keratoplasty, patients are at high risk for IOP increases, because they require chronic use of topical corticosteroids as prophylaxis against allograft rejection. For those who have undergone corneal transplantation for keratoconus or Fuchs endothelial dystrophy, the incidence of corticosteroid-induced IOP elevation $\geq 5 \mathrm{~mm} \mathrm{Hg}$ has been reported to be more than $60 \%$ within 4 years [42]. LE has been shown to successfully reverse mean IOP elevation induced by PA treatment, while preventing allograft rejection in patients after corneal transplantation [43]. In a retrospective analysis, 30 corneal transplant patients who developed IOP increases to $>21 \mathrm{~mm} \mathrm{Hg}$ with the use of PA 1.0\% (average dose of 2.4 times daily) were switched to LE suspension $0.5 \%$ at doses averaging 2.3 times daily at 3 weeks of use tapered down to 1-2 times daily by week 39 [43]. There was a lowering of mean IOP from 31.1 to $18.2 \mathrm{~mm} \mathrm{Hg}(P=0.0001)$ with $\mathrm{LE}$ treatment which averaged 21.6 weeks, with a mean percent IOP reduction of $32.6 \%$ at week 3 and $44.9 \%$ at week 39 .

The above findings are consistent with previous findings in subjects known to be corticosteroid responders. In a randomized, double-masked, crossover study where 19 known steroid responders received either LE suspension $0.5 \%$ or PA $1.0 \%$ four times daily for 42 days, followed by a washout period of at least 
14 days before crossing over to the other treatment, LE suspension $0.5 \%$ demonstrated less propensity to cause an IOP increase compared with PA $1.0 \%$ [44]. Subjects experienced increase of $4.1 \mathrm{~mm} \mathrm{Hg}$ while on LE treatment, which was not a significant difference from baseline, whereas treatment with PA resulted in significant mean IOP increases from baseline at all follow-up visits (mean IOP elevations of 5.9, 7.7, and $9.0 \mathrm{~mm} \mathrm{Hg}$ at days 14, 28, and 42, respectively; $P<0.05$ for all). By the Armaly classification [14], only one subject (7.1\%) in the LE group was identified as a high responder (>15 mm Hg increase) by day 42 , compared with four subjects $(30.8 \%)$ in the PA group.

\section{Dry Eye Disease}

DED is now widely recognized as having an ocular surface inflammatory component, and suppression of inflammation has been shown to reduce the signs and symptoms of this chronic condition [45-47]. Topically administered LE may have a role in anti-inflammatory therapy for DED and several studies evaluating the efficacy of LE suspension for this condition have also investigated the ramifications on IOP [48-54]. A pilot clinical trial compared the efficacy and safety of LE $0.5 \%$ to vehicle for reduction of clinical inflammatory signs and symptoms in patients with DED and delayed tear clearance [48]. Sixty-six patients were randomly assigned to receive either LE suspension $0.5 \%$ or vehicle four times daily for 4 weeks; none of the LE-treated patients developed clinically significant IOP elevation during the study. In an open-label masked study of 50 patients with moderate to severe DED, Villani et al. [49] demonstrated that there was no clinically significant IOP elevation during a regimen of LE suspension $0.5 \%$ administered four times a day for 4 weeks.

Recent clinical studies suggest that long-term administration of LE suspension $0.5 \%$ has minimal effect on IOP when used in the treatment of inflammation associated with DED [50-54]. In a randomized, controlled clinical trial of dry eye patients who had undergone hematopoietic stem cell transplantation, there was no IOP elevation $\geq 10 \mathrm{~mm} \mathrm{Hg}$ over baseline at any study visit in either LE-treated (76 eyes of 38 patients; treated twice daily) or cyclosporine A-treated eyes (74 eyes of 37 patients; treated twice daily) over a period of 12 months [50]. Likewise, Sheppard et al. [51] also reported no significant IOP elevation (defined as two consecutive visits with an IOP increase of $6 \mathrm{~mm} \mathrm{Hg}$ above baseline) in 36 patients with chronic dry eye pretreated with LE $0.5 \%$ twice a day for 2-16 months, followed by concurrent treatment with LE and cyclosporine A for 3-6 months. In a more recent prospective, multi-center clinical study also reported by Sheppard et al. [52], 112 patients with DED were randomly assigned to treatment with either LE $(n=57)$ or artificial tears $(n=55)$ four times per day for 2 weeks, followed by topical cyclosporine A twice per day with either LE twice per day or artificial tear twice per day for an additional 6 weeks. Mean IOP did not increase from baseline with either treatment, nor did it differ between the two groups. Three LE-treated patients had an IOP increase, compared with two in the artificial tear group (degree of increase not reported). Jung et al. [53] compared long-term (2 years) outcomes of LE $0.5 \%$ and FML $0.1 \%$ (both administered twice daily) for severe dry eye associated with Sjögren's syndrome in a retrospective analysis. There were no significant increases in mean IOP 
in either treatment group (LE: $n=66$; FML: $n=67$ ) over the course of the study and no patient required IOP-lowering medication. At 24 months, 4 patients treated with LE (6.1\%) versus 9 treated with FML (13.4\%) had an IOP elevation of $>2 \mathrm{~mm} \mathrm{Hg}$ compared with baseline. In these patients, those treated with LE had a lower mean IOP than the ones treated with FML $(15.0 \pm 0.8$ vs. $16.5 \pm 1.1 \mathrm{~mm} \mathrm{Hg}, P=0.04)$. Lee et al. [54] reported a randomized controlled trial of LE suspension $0.5 \%$ used four times daily along with eyelid scrubs and warm compresses in 34 patients with moderate or severe meibomian gland dysfunction. During the 2-month treatment period, no cases of clinically significant IOP increase were observed.

\section{Ocular Allergy}

A number of studies corroborate data obtained in the pivotal trials indicating that LE suspension $0.2 \%$ is safe in the treatment of allergic conjunctivitis. Gong et al. [55] reported that LE $0.2 \%$ was comparable to olopatadine $0.1 \%$ in efficacy and safety in 300 Chinese patients with seasonal allergic conjunctivitis. In this investigator-masked, parallel-group study, patients were randomized to either LE suspension four times a day or olopatadine twice a day for 15 days. No clinically significant IOP elevation occurred with either treatment, while nine patients in the LE $0.2 \%$ group and four patients in the olopatadine groups experienced an increase in IOP of $\geq 5 \mathrm{~mm} \mathrm{Hg}$.

LE $\quad 0.2 \%$ also demonstrated favorable long-term safety and tolerability in patients with allergic inflammation. In a retrospective study of 159 patients with seasonal and perennial allergic conjunctivitis, Ilyas et al. [56] found no instances of IOP elevation (defined as $>5 \mathrm{~mm} \mathrm{Hg}$ above baseline) with continuous use of LE $0.2 \%$ (1-4 times daily) for more than 12 months. Oner et al. [57] recently evaluated the efficacy and safety of LE suspension $0.5 \%$ compared with PA $1.0 \%$ and FML $0.1 \%$ in a parallel randomized trial in 60 patients with vernal conjunctivitis. Both PA and LE were more effective than FML in reducing the symptoms and signs of vernal conjunctivitis when administered four times daily for 28 days. However, there was a significant elevation of mean IOP in the PA group after day $3(P<0.001)$, which remained elevated $(P<0.001)$ even after three patients were discontinued because of IOP increases.

One study and a case report have associated short-term use of LE suspension $0.2 \%$ with elevations of IOP. In a randomized, double-masked study of 20 patients with seasonal or perennial allergic conjunctivitis undergoing a conjunctival allergen challenge, Berdy et al. [58] identified a small but significant increase in mean IOP (mean $\pm \mathrm{SD}$ : $1.6 \pm 2.08 \mathrm{~mm} \mathrm{Hg}, \quad P<0.001) \quad$ following a 14-day treatment period of LE $0.2 \%$ four times daily. $\mathrm{Lu}$ et al. [59] reported the case of a 29-year-old male Asian/Pacific Islander whose IOP increased to $50 \mathrm{~mm} \mathrm{Hg}$ in both eyes after receiving topical LE $0.2 \%$ (four times a day) for 3 days for chronic red eye presumed to be associated with soft contact lens wear. What is notable about this case is the patient's young age and Asian descent; both considered risk factors for steroid-induced IOP elevation [17, 18]. The patient's IOP returned to normal upon LE discontinuation, with no reported glaucomatous damage. 
NEWER FORMULATIONS OF LE: IOP-SAFETY PROFILE

\section{LE/Tobramycin}

In 2004, the FDA approved use of an LE $0.5 \% /$ tobramycin $0.3 \%$ (LE/T) suspension for corticosteroid-responsive inflammatory ocular conditions where superficial bacterial ocular infection or a risk of bacterial ocular infection exists. In a randomized, double-masked trial of 306 healthy volunteers treated with $\mathrm{LE} / \mathrm{T}$ or dexamethasone $0.1 \% /$ tobramycin $0.3 \%$ (DM/T; TobraDex $^{\circledR}$, Alcon, Fort Worth, TX, USA) four times daily for 4 weeks, the DM/T group had an increase in mean IOP from baseline at all study visits $(P<0.0001)$, whereas there was no significant elevation with LE/T $(P>0.61)$. More subjects in the DM/T group (11 subjects, $7.48 \%$ ) experienced IOP elevations $\geq 10 \mathrm{~mm} \mathrm{Hg}$ than in the LE/T group (three subjects, $1.95 \%$; $P=0.028$ ) [60]. Thanathanee and colleagues [61] compared the safety of LE/T and DM/T in a randomized controlled study in 32 patients undergoing PRK. The patients were randomized to receive $\mathrm{LE} / \mathrm{T}$ or $\mathrm{DM} / \mathrm{T}$ four times daily for 1 month after surgery. Consistent with previous findings that LE is safe for routine postoperative treatment after PRK, one patient receiving LE/T and three patients receiving DM/T experienced an IOP increase $\geq 5 \mathrm{~mm} \mathrm{Hg}$ from baseline $(P=0.60)$. The IOP returned to normal within 1 month in these patients after discontinuation of treatment.

Several studies have examined the clinical safety of LE/T suspension compared with DM/T in the treatment of blepharokeratoconjunctivitis, an inflammatory eyelid margin disease with secondary conjunctival and corneal involvement. Rhee and Mah [62] reported that neither treatment had a clinically significant effect on mean IOP when administered twice daily for 3-5 days in a controlled single-center study in 40 patients. White and colleagues [63] compared the safety of LE/T and DM/T in 276 patients in a randomized, investigator-masked, parallel-group, multi-center study using the recommended regimen of four times daily for 2 weeks. In contrast to the observation made by Rhee and Mah [62], White and colleagues [63] found a significant difference between LE/T and $\mathrm{DM} / \mathrm{T}$ in terms of the mean change from baseline in IOP $(-0.1 \pm 2.2$ vs. $0.6 \pm 2.3 \mathrm{~mm} \mathrm{Hg}$ at day 7 , $P=0.03 ;-0.1 \pm 2.4$ vs. $1.0 \pm 3.0 \mathrm{~mm} \mathrm{Hg}$ at day $15, \quad P=0.01$ for $\mathrm{LE} / \mathrm{T}$ and $\mathrm{DM} / \mathrm{T}$, respectively). Over the course of the study, 7.1\% of the LE/T-treated patients versus $14.4 \%$ of the $\mathrm{DM} / \mathrm{T}$-treated patients had an increase in IOP of 5-9 $\mathrm{mm} \mathrm{Hg}$. One patient in the $\mathrm{DM} / \mathrm{T}$ group experienced an IOP increase $\geq 10 \mathrm{~mm} \mathrm{Hg}$. These results are in accord with another randomized comparative multicenter clinical trial of 354 Chinese patients [64]. In this study, patients receiving DM/T had a significantly greater IOP increase from baseline at all follow-up visits as compared to patients receiving LE/T, both dosed four times daily for 2 weeks $(P \leq 0.0186)$. Patients treated with $\mathrm{DM} / \mathrm{T}$ also had approximately twice as many IOP elevations as compared to those receiving $\mathrm{LE} / \mathrm{T}$ of $\geq 5 \mathrm{~mm} \mathrm{Hg}$ ( $26 \%$ vs. $13 \%$, $P=0.0020)$ and $\geq 10 \mathrm{~mm} \mathrm{Hg}(3.4 \%$ vs. $7.3 \%$, $P=0.0958)$. Unlike the study by White et al. [63], where no patients treated with LE/T had an IOP increase $\geq 10 \mathrm{~mm} \mathrm{Hg}$, six LE/T-treated patients in the Chinese study experienced a clinically significant IOP increase. This difference was ascribed by the authors to multiple factors including racial diversity and patient age [64].

The effect of topical corticosteroids on IOP elevation in children is largely unknown. One study suggests that children have a lower rate of ocular hypertensive response to topical corticosteroids [65], while others have reported 
a more pronounced steroid-induced IOP effect than in the adult population $[66,67]$. The results of two small randomized controlled clinical studies suggest that short-term LE/T therapy is safe in children (aged 0-6 years) with eyelid inflammation or blepharoconjunctivitis [68]. Patients with eyelid inflammation received LE/T four times daily for 7 days followed by twice daily for 7 days; those with blepharoconjunctivitis received LE/T four times daily for 14 days. Mean IOP and IOP changes from baseline, assessed only in the lid inflammation study, were not different between LE/T and vehicle groups at any study visits during 2 weeks of treatment. All study eye IOPs were $<30 \mathrm{~mm} \mathrm{Hg}$, and all changes from baseline IOP were $<10 \mathrm{~mm} \mathrm{Hg}$ throughout the study.

\section{LE Ointment}

LE ointment $0.5 \%$ received FDA approval for treatment of postoperative inflammation and pain following ocular surgery based on two randomized, double-masked, parallel-group, vehicle-controlled clinical trials involving a total of more than 800 cataract surgery patients. An integrated analysis of data from these two studies indicates that mean IOP was consistently lower than baseline over the course of the study in both treatment groups when administered four times daily for 14 days following surgery [69]. The incidence of clinically significant IOP elevation did not differ between the treatment groups (three LE-treated patients and one vehicle-treated patient).

In addition to postoperative management of cataract surgery, LE ointment has been proposed as part of the perioperative regimen for surgical removal of pterygium [70, 71]. However, no IOP-safety data were identified in the literature for this usage during this review.

\section{LE Gel}

The gel formulation of LE $0.5 \%$ was approved in 2012 for the treatment of postoperative pain and inflammation following ocular surgery. LE gel $0.5 \%$ was well tolerated and had a good safety profile in comparison with vehicle in two identical randomized, controlled clinical studies in patients undergoing cataract surgery $[72,73]$. In each study $(n=407$ and 406, respectively), patients with anterior chamber inflammation following cataract surgery were randomized to LE gel or vehicle four times daily for two weeks. In both studies, mean IOP decreased over the treatment period in each group, and only one LE-treated patient developed a clinically significant elevation in IOP in each study (one of which was not considered related to the study treatment), compared with 1 and 0 vehicle-treated patients, respectively.

Post-approval studies on LE gel support the safety and tolerability of LE gel $0.5 \%$ in treating postoperative pain and inflammation following ocular surgery. Abessi et al. [74] reported equivalent effect of LE gel $0.5 \%$ and difluprednate $0.05 \%$ on IOP when used in the control of postoperative inflammation in cataract patients. Both corticosteroids were administered four times daily for 3 days prior to and 1 week post-surgery, followed by twice daily dosing for 1 week. No treatment-related clinically significant IOP elevations were observed and the two groups demonstrated no difference in mean IOP.

Three studies evaluated the effect of LE gel $0.5 \%$ on IOP over longer-term use. Salinger et al. [75] conducted a retrospective chart review of laser-assisted in situ keratomileusis (LASIK) and PRK patients ( $n=96$ and $n=108$ patients, respectively) treated with LE gel for control of postoperative inflammation and pain. During 
the first postoperative week, LE gel was prescribed most frequently as one drop four times daily. The most common duration of postoperative LE gel therapy was 7-14 days for LASIK patients and 30 days or longer for PRK patients. There were no IOP increases of $\geq 10 \mathrm{~mm} \mathrm{Hg}$ at any postoperative visit in the LASIK patients, while two cases of clinically significant IOP elevations were observed in the PRK patients. Smaller elevations in IOP of $\geq 5 \mathrm{~mm} \mathrm{Hg}$ were observed in two LASIK patients and 32 PRK patients over the course of the study.

Price and colleagues [76] compared the efficacy and safety of LE gel $0.5 \%$ and PA $1 \%$ in preventing immunologic rejection episodes after Descemet's membrane endothelial keratoplasty (DMEK) in a randomized investigator-masked controlled trial. A total of 167 patients were randomized to LE gel or PA four times daily for 2 months, followed by three times daily for a month, twice daily for a month, and once daily for 7 months. PA $1 \%$ treatment was twice as likely (relative risk: 2.3, 95\% confidence interval: $1.2-4.5, P=0.016$ ) as LE gel to induce IOP elevation (defined as IOP $\geq 24 \mathrm{~mm} \mathrm{Hg}$ or an increase $\geq 10 \mathrm{~mm} \mathrm{Hg}$ from baseline). In PA-treated eyes, a significantly higher proportion (20\%) of patients had a clinically significant increase in IOP as compared to LE gel-treated eyes (7.3\%; $P=0.013)$.

Finally, use of LE gel as either a monotherapy or induction therapy prior to treatment with $0.05 \%$ cyclosporine emulsion (CsA) was recently investigated in 102 patients with mild or moderate DED [77]. Subjects were randomized to a 12 week treatment with LE gel alone $(n=36)$, LE gel instilled on weeks $1-4$ and CsA instilled on weeks 2-12 $(n=33$; induction), or CsA alone $(n=33)$, all with twice daily administration. Mean IOP in the
LE monotherapy group was not statistically different from that in the CsA monotherapy group $(P \geq 0.07)$. At week 12 , only one subject in the monotherapy group had an IOP of $34 \mathrm{~mm} \mathrm{Hg}$ bilaterally and one subject in the induction therapy group had an IOP of $26 \mathrm{~mm} \mathrm{Hg}$ bilaterally.

\section{CUMULATIVE IOP ELEVATION INCIDENCE RATES ACROSS PUBLISHED STUDIES}

The incidence of IOP elevations from studies which defined clinically significant IOP increase as $\geq 10 \mathrm{~mm} \mathrm{Hg}$ were pooled to provide an aggregate rate of IOP elevation. Of all subjects that received short-term LE treatment, $0.8 \%$ (14/1725 subjects) had clinically significant IOP elevations (Table 1; Fig. 2). With long-term LE treatment, excluding those subjects known to be wearing contact lenses during treatment, the overall incidence of IOP elevation was 1.5\% (21/ 1386 subjects)—slightly higher than the $0.6 \%$ incidence rate (4/624 subjects) reported by Novack et al. [34] (Table 2; Fig. 2). When pooling data from studies with vehicle or active control groups, the cumulative incidence of clinically significant IOP elevation was similar to vehicle $[0.6 \%(9 / 1407)$ vs. $0.4 \%(6 / 1365), P=0.646]$, but considerably lower than those of patients treated with PA [3.4\% (10/291) vs. $11.3 \%(33 / 292), P<0.001]$ or $\mathrm{DM} / \mathrm{T} \quad[1.8 \% \quad(9 / 491)$ vs. $5.2 \% \quad(25 / 485)$, $P=0.008$; Tables 1, 2; Fig. 3].

\section{CONCLUSIONS}

Evidence from published data indicates that topical treatment with LE has minimal effect on IOP when used in the treatment of a wide range of ocular surface and intraocular inflammatory 


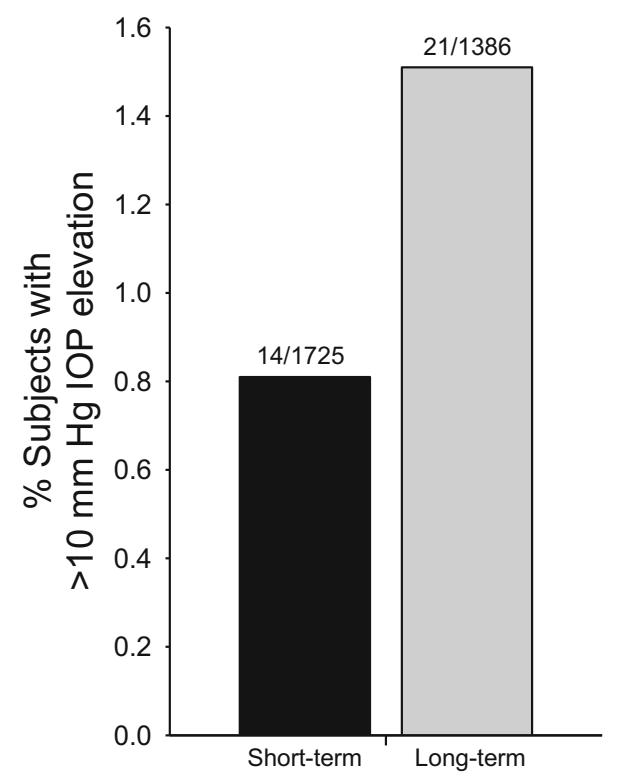

Fig. 2 Cumulative rates of clinically significant IOP elevation with loteprednol etabonate. Short-term ( $<28$ days) and long-term ( $\geq 28$ days) IOP elevation for all loteprednol etabonate formulations (pooled from 12 studies for short term and 18 studies for long term). For long-term studies, giant papillary conjunctivitis studies are excluded. Clinically significant IOP elevation is defined as $\geq 10 \mathrm{~mm} \mathrm{Hg}$ (refer to Tables 1, 2). IOP intraocular pressure

disorders, including ocular allergy, DED, anterior uveitis, penetrating keratoplasty, endothelial keratoplasty, and postoperative pain and inflammation following ocular surgery. In all studies, LE consistently demonstrated a low propensity to elevate IOP, regardless of formulation, dosage regimen, or treatment duration, including in known steroid responders. The topical C-20 ester corticosteroid has consistently demonstrated a low propensity to increase IOP even in known steroid responders. This improved safety profile makes LE therapy an advantageous treatment option for ocular inflammation, especially in cases where chronic use of a topical corticosteroid is necessary, but limited by a higher risk for ocular hypertension. That said, more head-to-head studies comparing the newer formulations of

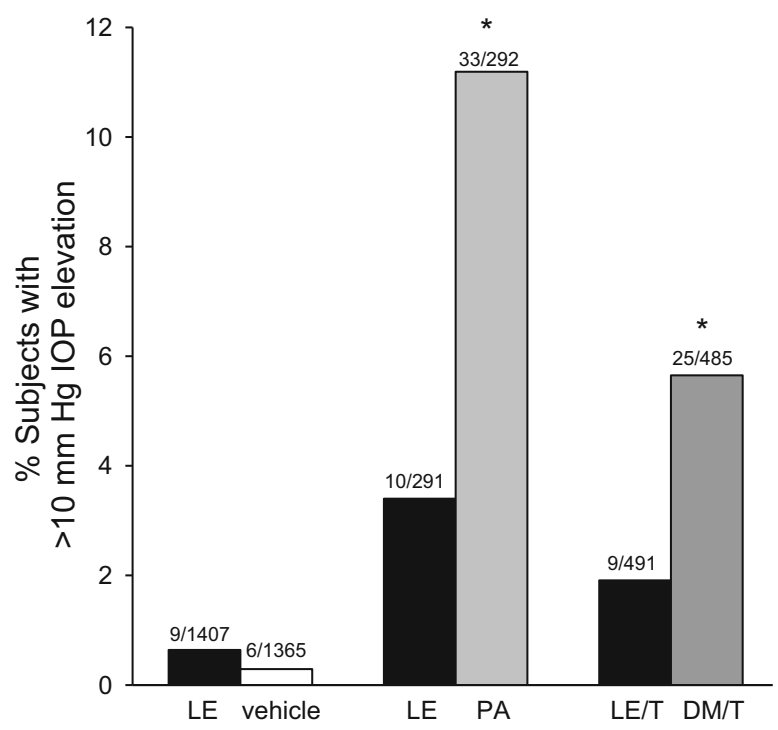

Fig. 3 Cumulative rates of clinically significant IOP elevation in head-to-head studies. The proportion of subjects with $\geq 10 \mathrm{~mm} \mathrm{Hg}$ IOP elevation in vehicle or active control studies of LE suspension and gel formulations compared to vehicle (ten studies) or PA $1 \%$ (five studies) and of $\mathrm{LE} / \mathrm{T}$ vs. $\mathrm{DM} / \mathrm{T}$ (four studies). ${ }^{*} P<0.01$ vs. comparator. $D M / T$ dexamethasone $0.1 \% /$ tobramycin $0.3 \%$ suspension, $L E$ loteprednol etabonate, $L E / T$ loteprednol etabonate $0.5 \% /$ tobramycin $0.3 \%$ suspension, IOP intraocular pressure, $P A$ prednisolone acetate

LE and other topical corticosteroids, especially newer topical corticosteroids such as difluprednate, are warranted to better understand the relative safety of currently available corticosteroid treatment options for ocular inflammation.

\section{ACKNOWLEDGMENTS}

The article processing charges and open access fee for this publication were funded by Bausch + Lomb. All named authors meet the International Committee of Medical Journal Editors (ICMJE) criteria for authorship for this manuscript, take responsibility for the integrity of the work as a whole, and have given final approval to the version to be published. The 
authors did not receive any funding to prepare this review. Editorial assistance in the preparation of this manuscript was provided by Ethis Communications Inc. Support for this assistance was funded by Bausch + Lomb. The authors thank Heleen H. DeCory (Bausch + Lomb) for critical review of content and editing of the manuscript.

Disclosures. John D. Sheppard is a consultant for Bausch + Lomb, a division of Valeant Pharmaceuticals. Timothy L. Comstock is a consultant for Bausch + Lomb, a division of Valeant Pharmaceuticals. Megan E. Cavet is an employee of Bausch + Lomb.

Compliance with Ethics Guidelines. This article is based on previously conducted studies and does not involve any new studies of human or animal subjects performed by any of the authors.

Open Access. This article is distributed under the terms of the Creative Commons Attribution-NonCommercial 4.0 International License (http://creativecommons.org/licenses/ by-nc/4.0/), which permits any noncommercial use, distribution, and reproduction in any medium, provided you give appropriate credit to the original author(s) and the source, provide a link to the Creative Commons license, and indicate if changes were made.

\section{REFERENCES}

1. Barnes PJ. Corticosteroid effects on cell signalling. Eur Respir J. 2006;27(2):413-26.

2. Gupte R, Muse GW, Chinenov Y, Adelman K, Rogatsky I. Glucocorticoid receptor represses proinflammatory genes at distinct steps of the transcription cycle. Proc Natl Acad Sci USA. 2013;110(36):14616-21.
3. Rhen T, Cidlowski JA. Antiinflammatory action of glucocorticoids-new mechanisms for old drugs. N Engl J Med. 2005;353(16):1711-23.

4. Sendrowski DP JSD, Semes LP, Stern ME Anti-inflammatory Drugs. In: Bartlett JD, JS, editor. Clinical Ocular Pharmacology: Elsevier 2008;12:221-44.

5. Bielory BP, Perez VL, Bielory L. Treatment of seasonal allergic conjunctivitis with ophthalmic corticosteroids: in search of the perfect ocular corticosteroids in the treatment of allergic conjunctivitis. Curr Opin Allergy Clin Immunol. 2010;10(5):469-77.

6. Leonardi A. The central role of conjunctival mast cells in the pathogenesis of ocular allergy. Curr Allergy Asthma Rep. 2002;2(4):325-31.

7. McGhee CN, Dean S, Danesh-Meyer H. Locally administered ocular corticosteroids: benefits and risks. Drug Saf. 2002;25(1):33-55.

8. Pavesio CE, Decory HH. Treatment of ocular inflammatory conditions with loteprednol etabonate. Br J Ophthalmol. 2008;92(4):455-9.

9. Kersey JP, Broadway DC. Corticosteroid-induced glaucoma: a review of the literature. Eye (Lond). 2006;20(4):407-16.

10. Razeghinejad MR, Katz LJ. Steroid-induced iatrogenic glaucoma. Ophthalmic Res. 2012;47(2):66-80.

11. Razeghinejad MR, Myers JS, Katz LJ. Iatrogenic glaucoma secondary to medications. Am J Med. 2011;124(1):20-5.

12. Pleyer U, Ursell PG, Rama P. Intraocular pressure effects of common topical steroids for post-cataract inflammation: are they all the same? Ophthalmol Ther. 2013;2(2):55-72.

13. Cantrill HL, Palmberg PF, Zink HA, Waltman SR, Podos SM, Becker B. Comparison of in vitro potency of corticosteroids with ability to raise intraocular pressure. Am J Ophthalmol. 1975;79(6):1012-7.

14. Armaly MF. Statistical attributes of the steroid hypertensive response in the clinically normal eye. I. The demonstration of three levels of response. Invest Ophthalmol. 1965;4:187-97.

15. Becker B. Intraocular pressure response to topical corticosteroids. 1965;4:198-205.

16. Urban RC Jr, Dreyer EB. Corticosteroid-induced glaucoma. Int Ophthalmol Clin. 1993;33(2):135-9. 
17. Chang DF, Tan JJ, Tripodis Y. Risk factors for steroid response among cataract patients. J Cataract Refract Surg. 2011;37(4):675-81.

18. Shukla D, Vidhya N, Prasad NM, Mahalakshmi R, Kolluru C, Krishnadas R. Evaluation of patient age as a risk factor for intraocular pressure elevation after intravitreal triamcinolone. Am J Ophthalmol. 2007;144(3):453-4.

19. Spaeth GL, Monteiro de Barros DS, Fudemberg SJ. Visual loss caused by corticosteroid-induced glaucoma: how to avoid it. Retina. 2009;29(8):1057-61.

20. Tripathi RC, Parapuram SK, Tripathi BJ, Zhong Y, Chalam KV. Corticosteroids and glaucoma risk. Drugs Aging. 1999;15(6):439-50.

21. Bodor N. Design of novel soft corticosteroids. Curr Probl Dermatol. 1993;21:11-9.

22. Bodor N. Designing safer ophthalmic drugs by soft drug approaches. J Ocul Pharmacol. 1994;10(1):3-15.

23. Bodor N, Buchwald P. Ophthalmic drug design based on the metabolic activity of the eye: soft drugs and chemical delivery systems. AAPS J. 2005;7(4):E820-33.

24. Druzgala P, Hochhaus G, Bodor N. Soft drugs- -10 . Blanching activity and receptor binding affinity of a new type of glucocorticoid: loteprednol etabonate. J Steroid Biochem Mol Biol. 1991;38(2):149-54.

25. Druzgala P, Wu WM, Bodor N. Ocular absorption and distribution of loteprednol etabonate, a soft steroid, in rabbit eyes. Curr Eye Res. 1991;10(10):933-7.

26. A double-masked, placebo-controlled evaluation of $0.5 \%$ loteprednol etabonate in the treatment of postoperative inflammation. The Loteprednol Etabonate Postoperative Inflammation Study Group 2. Ophthalmology. 1998;105(9):1780-6.

27. Controlled evaluation of loteprednol etabonate and prednisolone acetate in the treatment of acute anterior uveitis. Loteprednol Etabonate US Uveitis Study Group. Am J Ophthalmol. 1999;127(5):537-44.

28. Asbell P, Howes J. A double-masked, placebo-controlled evaluation of the efficacy and safety of loteprednol etabonate in the treatment of giant papillary conjunctivitis. CLAO J. 1997;23(1):31-6.

29. Dell SJ, Lowry GM, Northcutt JA, Howes J, Novack GD, Hart K. A randomized, double-masked, placebo-controlled parallel study of $0.2 \%$ loteprednol etabonate in patients with seasonal allergic conjunctivitis. J Allergy Clin Immunol. 1998;102(2):251-5.

30. Dell SJ, Shulman DG, Lowry GM, Howes J. A controlled evaluation of the efficacy and safety of loteprednol etabonate in the prophylactic treatment of seasonal allergic conjunctivitis. Loteprednol Allergic Conjunctivitis Study Group. Am J Ophthalmol. 1997;123(6):791-7.

31. Friedlaender MH, Howes J. A double-masked, placebo-controlled evaluation of the efficacy and safety of loteprednol etabonate in the treatment of giant papillary conjunctivitis. The Loteprednol Etabonate Giant Papillary Conjunctivitis Study Group I. Am J Ophthalmol. 1997;123(4):455-64.

32. Shulman DG, Lothringer LL, Rubin JM, et al. A randomized, double-masked, placebo-controlled parallel study of loteprednol etabonate $0.2 \%$ in patients with seasonal allergic conjunctivitis. Ophthalmology. 1999;106(2):362-9.

33. Stewart R, Horwitz B, Howes J, Novack GD, Hart K. Double-masked, placebo-controlled evaluation of loteprednol etabonate $0.5 \%$ for postoperative inflammation. Loteprednol Etabonate Post-operative Inflammation Study Group 1. J Cataract Refract Surg. 1998;24(11):1480-9.

34. Novack GD, Howes J, Crockett RS, Sherwood MB. Change in intraocular pressure during long-term use of loteprednol etabonate. J Glaucoma. 1998;7(4):266-9.

35. Comstock TL, Decory HH. Advances in corticosteroid therapy for ocular inflammation: loteprednol etabonate. Int J Inflam. 2012;2012:789623.

36. Amon M, Busin M. Loteprednol etabonate ophthalmic suspension $0.5 \%$ : efficacy and safety for postoperative anti-inflammatory use. Int Ophthalmol. 2012;32(5):507-17.

37. Coffey MJ, Decory HH, Lane SS. Development of a non-settling gel formulation of $0.5 \%$ loteprednol etabonate for anti-inflammatory use as an ophthalmic drop. Clin Ophthalmol. 2013;7:299-312.

38. Lane SS, Holland EJ. Loteprednol etabonate $0.5 \%$ versus prednisolone acetate $1.0 \%$ for the treatment of inflammation after cataract surgery. J Cataract Refract Surg. 2013;39(2):168-73.

39. Bannale SG, Pundarikaksha HP, Sowbhagya HN. A prospective, open-label study to compare the efficacy and the safety of topical loteprednol etabonate and topical flurbiprofen sodium in patients with post-operative inflammation after 
cataract extraction. J Clin Diagn Res. 2012;6(9):1499-503.

40. Holzer MP, Solomon KD, Sandoval HP, Vroman DT. Comparison of ketorolac tromethamine $0.5 \%$ and loteprednol etabonate $0.5 \%$ for inflammation after phacoemulsification: prospective randomized double-masked study. J Cataract Refract Surg. 2002;28(1):93-9.

41. Mifflin MD, Leishman LL, Christiansen SM, Sikder S, Hsu M, Moshirfar M. Use of loteprednol for routine prophylaxis after photorefractive keratectomy. Clin Ophthalmol. 2012;6:653-9.

42. Erdurmus M, Cohen EJ, Yildiz EH, et al. Steroid-induced intraocular pressure elevation or glaucoma after penetrating keratoplasty in patients with keratoconus or Fuchs dystrophy. Cornea. 2009;28(7):759-64.

43. Holland EJ, Djalilian AR, Sanderson JP. Attenuation of ocular hypertension with the use of topical loteprednol etabonate $0.5 \%$ in steroid responders after corneal transplantation. Cornea. 2009;28(10):1139-43.

44. Bartlett JD, Horwitz B, Laibovitz R, Howes JF. Intraocular pressure response to loteprednol etabonate in known steroid responders. J Ocul Pharmacol. 1993;9(2):157-65.

45. The definition and classification of dry eye disease: report of the Definition and Classification Subcommittee of the International Dry Eye WorkShop (2007). Ocul Surf. 2007;5(2):75-92.

46. Hessen M, Akpek EK. Dry eye: an inflammatory ocular disease. J Ophthalmic Vis Res. 2014;9(2):240-50.

47. Wei Y, Asbell PA. The core mechanism of dry eye disease is inflammation. Eye Contact Lens. 2014;40(4):248-56.

48. Pflugfelder SC, Maskin SL, Anderson B, et al. A randomized, double-masked, placebo-controlled, multicenter comparison of loteprednol etabonate ophthalmic suspension, $0.5 \%$, and placebo for treatment of keratoconjunctivitis sicca in patients with delayed tear clearance. Am J Ophthalmol. 2004;138(3):444-57.

49. Villani E, Garoli E, Termine V, Pichi F, Ratiglia R, Nucci P. Corneal confocal microscopy in dry eye treated with corticosteroids. Optom Vis Sci. 2015;92(9):e290-5.

50. Boynton GE, Raoof D, Niziol LM, Hussain M, Mian SI. Prospective randomized trial comparing efficacy of topical loteprednol etabonate $0.5 \%$ versus
cyclosporine-A $0.05 \%$ for treatment of dry eye syndrome following hematopoietic stem cell transplantation. Cornea. 2015;34(7):725-32.

51. Sheppard JD, Scoper SV, Samudre S. Topical loteprednol pretreatment reduces cyclosporine stinging in chronic dry eye disease. J Ocul Pharmacol Ther. 2011;27(1):23-7.

52. Sheppard JD, Donnenfeld ED, Holland EJ, et al. Effect of loteprednol etabonate $0.5 \%$ on initiation of dry eye treatment with topical cyclosporine 0.05\%. Eye Contact Lens. 2014;40(5):289-96.

53. Jung HH, Ji YS, Sung MS, Kim KK, Yoon KC. Long-Term outcome of treatment with topical corticosteroids for severe dry eye associated with Sjogren's syndrome. Chonnam Med J. 2015;51(1):26-32.

54. Lee H, Chung B, Kim KS, Seo KY, Choi BJ, Kim TI. Effects of topical loteprednol etabonate on tear cytokines and clinical outcomes in moderate and severe meibomian gland dysfunction: randomized clinical trial. Am J Ophthalmol. 2014;158(6):1172-83 e1.

55. Gong L, Sun X, Qu J, et al. Loteprednol etabonate suspension $0.2 \%$ administered QID compared with olopatadine solution $0.1 \%$ administered BID in the treatment of seasonal allergic conjunctivitis: a multicenter, randomized, investigator-masked, parallel group study in Chinese patients. Clin Ther. 2012;34(6):1259-72 e1.

56. Ilyas H, Slonim CB, Braswell GR, Favetta JR, Schulman M. Long-term safety of loteprednol etabonate $0.2 \%$ in the treatment of seasonal and perennial allergic conjunctivitis. Eye Contact Lens. 2004;30(1):10-3.

57. Oner V, Turkcu FM, Tas M, Alakus MF, Iscan Y. Topical loteprednol etabonate $0.5 \%$ for treatment of vernal keratoconjunctivitis: efficacy and safety. Jpn J Ophthalmol. 2012;56(4):312-8.

58. Berdy GJ, Stoppel JO, Epstein AB. Comparison of the clinical efficacy and tolerability of olopatadine hydrochloride $0.1 \%$ ophthalmic solution and loteprednol etabonate $0.2 \%$ ophthalmic suspension in the conjunctival allergen challenge model. Clin Ther. 2002;24(6):918-29.

59. Lu E, Fujimoto LT, Vejabul PA, Jew RL. Steroid-induced ocular hypertension with loteprednol etabonate $0.2 \%-\mathrm{a}$ case report. Optometry. 2011;82(7):413-20.

60. Holland EJ, Bartlett JD, Paterno MR, Usner DW, Comstock TL. Effects of loteprednol/tobramycin versus dexamethasone/tobramycin on intraocular 
pressure in healthy volunteers. Cornea. 2008;27(1):50-5.

61. Thanathanee O, Sriphon P, Anutarapongpan O, et al. A randomized controlled trial comparing dexamethasone with loteprednol etabonate on postoperative photorefractive keratectomy. J Ocul Pharmacol Ther. 2015;31(3):165-8.

62. Rhee SS, Mah FS. Comparison of tobramycin $0.3 \%$ / dexamethasone $0.1 \%$ and tobramycin $0.3 \%$ / loteprednol $0.5 \%$ in the management of blepharo-keratoconjunctivitis. Adv Ther. 2007;24(1):60-7.

63. White EM, Macy JI, Bateman KM, Comstock TL. Comparison of the safety and efficacy of loteprednol $\quad 0.5 \% /$ tobramycin $\quad 0.3 \%$ with dexamethasone $0.1 \%$ /tobramycin $0.3 \%$ in the treatment of blepharokeratoconjunctivitis. Curr Med Res Opin. 2008;24(1):287-96.

64. Chen M, Gong L, Sun X, et al. A multicenter, randomized, parallel-group, clinical trial comparing the safety and efficacy of loteprednol etabonate $0.5 \% /$ tobramycin $0.3 \%$ with dexamethasone $0.1 \% /$ tobramycin $0.3 \%$ in the treatment of Chinese patients with blepharokeratoconjunctivitis. Curr Med Res Opin. 2012;28(3):385-94.

65. Biedner BZ, David R, Grudsky A, Sachs U. Intraocular pressure response to corticosteroids in children. Br J Ophthalmol. 1980;64(6):430-1.

66. Kwok AK, Lam DS, Ng JS, Fan DS, Chew SJ, Tso MO. Ocular-hypertensive response to topical steroids in children. Ophthalmology. 1997;104(12):2112-6.

67. Ohji M, Kinoshita S, Ohmi E, Kuwayama Y. Marked intraocular pressure response to instillation of corticosteroids in children. Am J Ophthalmol. 1991;112(4):450-4.

68. Comstock TL, Paterno MR, Bateman KM, Decory $\mathrm{HH}$, Gearinger M. Safety and tolerability of loteprednol etabonate $0.5 \%$ and tobramycin $0.3 \%$ ophthalmic suspension in pediatric subjects. Paediatr Drugs. 2012;14(2):119-30.

69. Comstock TL, Paterno MR, Singh A, Erb T, Davis E. Safety and efficacy of loteprednol etabonate ophthalmic ointment $0.5 \%$ for the treatment of inflammation and pain following cataract surgery. Clin Ophthalmol. 2011;5:177-86.

70. Nguyen HT, Samudre SS, Lattanzio FA, Williams PB, Sheppard JD. Loteprednol etabonate (Lotemax $0.5 \%)$ reduces inflammatory response associated with pterygium progression. Invest Ophthalmol Vis Sci. 2008;49(13):6027.

71. Sheppard JD, Mansur A, Comstock TL, Hovanesian JA. An update on the surgical management of pterygium and the role of loteprednol etabonate ointment. Clin Ophthalmol. 2014;8:1105-18.

72. Fong R, Leitritz $M$, Siou-Mermet $R$, Erb $T$. Loteprednol etabonate gel $0.5 \%$ for postoperative pain and inflammation after cataract surgery: results of a multicenter trial. Clin Ophthalmol. 2012;6:1113-24.

73. Rajpal RK, Roel L, Siou-Mermet R, Erb T. Efficacy and safety of loteprednol etabonate $0.5 \%$ gel in the treatment of ocular inflammation and pain after cataract surgery. J Cataract Refract Surg. 2013;39(2):158-67.

74. Abessi B, Schultze RL, Eden RA, Brooksby LM. Comparison of efficacy of difluprednate $0.05 \%$ and loteprednol gel $0.5 \%$ after cataract surgery. In: Paper presented at: American cataract and refractive surgery annual symposium and congress (ASCRS). 2015.

75. Salinger CL, Gordon $\mathrm{M}$, Jackson MA, Perl T, Donnenfeld E. A retrospective analysis of the postoperative use of loteprednol etabonate gel $0.5 \%$ following laser-assisted in situ keratomileusis or photorefractive keratectomy surgery. Clin Ophthalmol. 2015;9:2089-97.

76. Price MO, Feng MT, Scanameo A, Price FW Jr. Loteprednol etabonate $0.5 \%$ gel vs. prednisolone acetate $1 \%$ solution after descemet membrane endothelial keratoplasty: prospective randomized trial. Cornea. 2015;34(8):853-8.

77. Williams J, Evans D, Torkildesn G, Sheppard J. Safety and efficacy of Lotemax gel compared to Restasis in the treatment of inflammation associated with dry eye disease. In: Paper presented at Annual Meeting of American Academy of Optometry. 2014;Program Number 145034. 